\title{
KNOWLEDGE AND AWARENESS OF BASIC LIFE SUPPORT AMONG MEDICAL STAFFS OF BIRAT MEDICAL COLLEGE AND TEACHING HOSPITAL
}

\author{
Arjyal $B,{ }^{1 *}$ Rajbanshi $L K,{ }^{1}$ Kanal $K_{,}{ }^{2}$ Bajracharya $A^{1}$
}

\section{Affiliation}

1. Lecturer, Department of Anesthesiology and Critical Care, Birat Medical College and Teaching Hospital, Biratnagar

2. Consultant, Department of Anesthesiology and Critical Care, Birat Medical College and Teaching Hospital, Biratnagar

\section{ARTICLE INFO}

\section{Article History}

\begin{tabular}{|c|c|}
\hline Received & 27 February, 2019 \\
\hline Accepted & 21 April, 2019 \\
\hline Published & 30 April, 2019 \\
\hline
\end{tabular}

(c) Authors retain copyright and grant the journal right of first publication with the work simultaneously licensed under Creative Commons Attribution License CC - BY 4.0 that allows others to share the work with an acknowledgment of the work's authorship and initial publication in this journal.

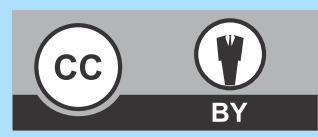

ORA 111

DOI: http://dx.doi.org/10.3126/bjhs.v4i1.23949

\section{* Corresponding Author}

Dr. Batsalya Arjyal Lecturer

Department of Anesthesiology and Critical Care Birat Medical College and Teaching Hospital, Biratnagar Email ID: batsalyaarjyal@gmail.com

ORCID ID: https://orcid.org/0000-0001-6939-4544

\section{Citation}

Arjyal B, Rajbanshi LK, Khanal K, Bajracharya A. Knowledge and Awareness of Basic Life Support among Medical Staffs of Birat Medical College and Teaching Hospital. BJHS 2019;4(1)8: 666 - 670.

\section{ABSTRACT}

\section{Introduction}

It is essential that all the medical professionals should have adequate skill for basic life support (BLS) for better outcome of cardiac arrest patients. The objective of the study is to assess the knowledge and awareness of BLS among the medical doctors, nursing staffs and health care paramedics working in Birat Medical College and Teaching Hospital, Biratnagar.

\section{Methodology}

A three-month duration observational questionnaire-based survey was conducted at Birat Medical College and Teaching Hospital, Biratnagar to assess the knowledge, awareness of basic life support among the medical doctors, nursing staffs and health care paramedics. A total of ten questions were designed to assess the knowledge and awareness regarding BLS skill. Three questions were designed to assess the previous experiences on cardiac arrest situation and BLS training. Similarly, two additional questions were added to assess the self-grading of BLS knowledge which included poor, below average, good and excellent.

\section{Result}

It was observed that only $14 \%$ participants had previous BLS training. Surprisingly, $76 \%$ of the participants had encountered cardiac arrest situation in their clinical practice but they were managing those cases with limited knowledge on BLS. The correct answer to the self-structured questionnaire were ticked by less than $50 \%$ of participants and majority of the participants came below average on self-grading of the knowledge and awareness suggesting the need of easy accessibility of BLS training centers in the eastern part of Nepal.

\section{Conclusion}

This study revealed that the knowledge and awareness of basic life support skills among the various staffs was mostly below average to poor. Significant amount of cost effective BLS trainings must be conducted so as to develop competent staffs by various training centers

\section{KEYWORDS}

Awareness, basic life support, cardiopulmonary resuscitation, knowledge 


\section{INTRODUCTION}

Cardiac arrest is a medical emergency which requires early detection and prompt initiation of resuscitative effort that can improve the survival rate. Basic life support(BLS) includes early detection of cardiac arrest in patients, basic airway management, initiation of effective chest compression and early use of automated external defibrillation. ${ }^{1,2}$ Effective basic life support can improve the survival rate of patients with cardiac arrest at the time of discharge and at 90 days and are less likely to have poor neurological function ${ }^{3}$ The outcome of cardiac arrest patient is determined by the fact that how early and effectively BLS is initiated. The survival chance increases by two-fold if basic life support (BLS) is initiated by the first person intervening the patient and if automated external defibrillators (AED) has been used at the earliest moment. ${ }^{4}$

It is important that all medical and paramedical staffs acquire a BLS training as they come across life-threatening emergencies in their routine life. ${ }^{5,6}$ As cardiac arrest can happen anytime, anywhere and to anyone, even the general non-medical population should learn BLS skill. Knowledge of BLS and practice of simple cardio pulmonary resuscitation (CPR) techniques ensures the survival of the patient long enough till experienced medical help arrives and in most cases is itself sufficient for survival.

BLS skill training in the resource limited countries like Nepal is a challenging task. Most of the health professional in the eastern part of Nepal lack basic life support training. The possible reason could be the lack of awareness, lack of training program. Clinical practice without the skill and knowledge of BLS has a negative impact on the survival of patient with life threatening emergencies. Regular training on BLS is essential to improvise the skills and knowledge of BLS among the health care professionals. For this it is equally important to assess the basic knowledge level regarding BLS so that the effective training programs can be formulated and designed for health care providers. There are very limited data from the eastern part of Nepal assessing the knowledge and awareness of BLS among health care providers. So, this study was designed to investigate the knowledge and awareness regarding BLS among the medical doctors, nursing staffs and health care paramedics working in Birat Medical College and Teaching Hospital, Biratnagar.

\section{METHODOLOGY}

This was an observational cross-sectional questionnairebased survey assessing the knowledge and awareness regarding basic life support skill of medical staffs working at Birat Medical College and Teaching Hospital and Biratnagar Aspatal Pvt Ltd was conducted within a duration of three months (2018-11-1 to 2019-2-30). Ethical clearance was obtained from the institutional review committee (IRC-PA003/2075-76) on 2018-10-28.

A self-designed questionnaire was developed which included ten questions to assess the knowledge and awareness regarding BLS skill. Three questions were designed to assess the previous experiences on cardiac arrest situation and BLS training. Similarly, two additional questions were added to assess the self-grading of BLS knowledge which included poor., below average, good and excellent. The questionnaire was distributed to the available consultants in various clinical and non-clinical departments of the institute, medical officers, nursing staffs and health paramedics working in various departments and were collected within 24 hours.
A pilot study including 30 participants was done at Biratnagar Aspatal to calculate the same size. This pilot study showed only $16 \%$ of the participants had a formal training of basic life support. Considering level of acceptance as $5 \%$ (type 1 error) and $80 \%$ of power of study and absolute error of $5 \%$ the sample size was calculated as follows:

$$
(1.96)^{2} \times 0.16(1-0.16) \div(0.05)^{2}=206
$$

So, considering a $15 \%$ drop outs, at least 250 participants were included in the study.

Those not willing to take part in the study or who did not return questionnaires not returned within 24 hours or partially filled questionnaires were excluded from the study.

\section{RESULTS}

A total of 250 self-structured questionnaires assessing the knowledge and awareness on basic life support skill were distributed among the various staffs at Birat Medical College Teaching Hospital and Biratnagar Aspatal Pvt Ltd. Data was entered in MS excel and statistical analysis was done by IBM SPSS version 23 . The study included only categorized data which presented as the frequency and percentage. The result obtained was presented in tabular and graphical design.

The consort diagram of the participants of the study is demonstrated in fig 1.Majority of the participants in the study were nursing staffs.

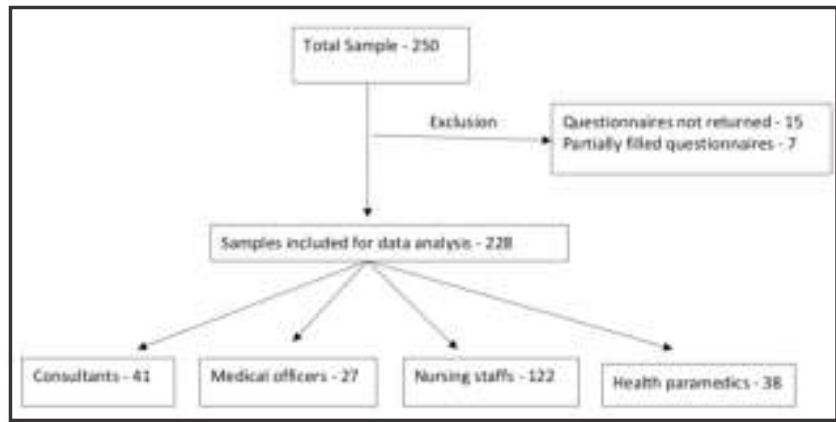

Figure 1: Consort Diagram for Participants.

The demographic profile and years of experiences of work in the institute is given in the table 1. Majority of the participants were in the age group of 20 to 40 years with the female participants dominating the male participants (57.89\% vs $42.10 \%)$. About $40.35 \%$ of participants had an experience of work of one to two years while $32.01 \%$ of participants were working for more than two years in the institute.

\begin{tabular}{|c|c|c|c|}
\hline \multicolumn{2}{|l|}{ Variables } & Number ( $n=228$ ) & Percentage (\%) \\
\hline \multirow[t]{4}{*}{ Age } & 10-20yrs. & 23 & 10.08 \\
\hline & $20-40$ yrs. & 188 & 82.45 \\
\hline & $40-60$ yrs. & 15 & 6.57 \\
\hline & $>60$ yrs. & 2 & 0.87 \\
\hline \multirow[t]{2}{*}{ Sex } & Male & 96 & 42.10 \\
\hline & Female & 132 & 57.89 \\
\hline \multirow{4}{*}{$\begin{array}{l}\text { Years of } \\
\text { experiences }\end{array}$} & $<1 \mathrm{yr}$. & 35 & 15.35 \\
\hline & $1-2$ yrs. & 92 & 40.35 \\
\hline & $2-4$ yrs. & 73 & 32.01 \\
\hline & $>4$ yrs. & 28 & 12.28 \\
\hline
\end{tabular}


On asking about the previous exposure to any of basic life support training or workshop, only few of the participants had previous training of BLS (14.03\%, fig 2$)$.

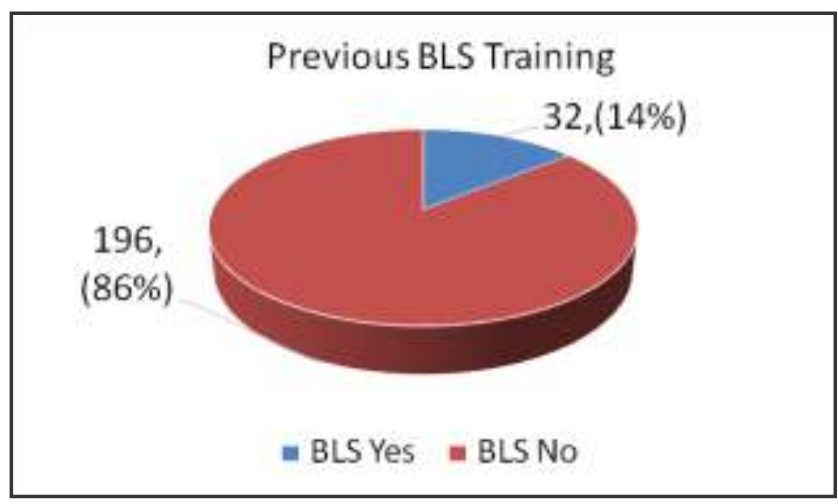

Figure 2: Previous BLS training.

Figure 3 shows the distribution of the participants who had previous encounter with the cardiac arrest situation. Majority of the participants (76\%) had previous experience of cardiac arrest condition during their clinical experiences inside and outside the hospital.

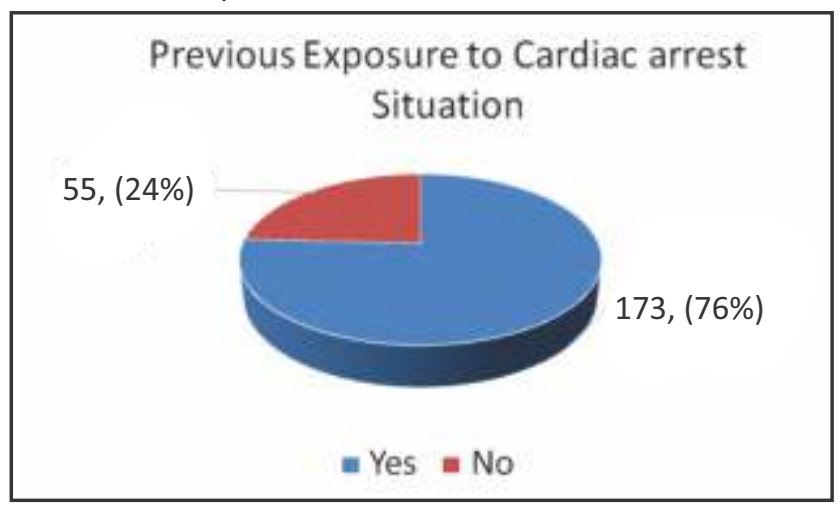

Figure 3: Previous exposure to cardiac arrest condition

On asking to those participants who had encountered cardiac arrest situation regarding their response to the patient, majority of participants $(60.6 \%)$ responded that they had started cardiac compression immediately. They were atleast aware of the fact that cardiac arrest can be revived with the chest compression if it was started immediately. About $5.7 \%$ of the participant remained ignorant to the situation (Fig 4)

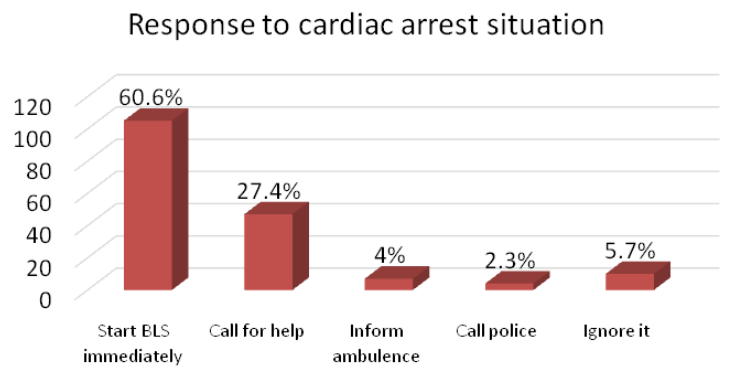

Figure 4: Response to cardiac arrest situation

Ten questions were designed to assess the knowledge, awareness regarding skill of basic life support (Table 2). Only $34.2 \%$ of the participants were aware of the sign of cardiac arrest recommended by American Heart Association (AHA). Similarly, only $40.3 \%$ correctly answered the initial response to the cardiac arrest patient. Very few of the participants (36.4\%) knew about the correct method of checking pulse. Similarly, very unsatisfied number of participants answered correctly regarding the questions asked about the maximum time allowed for pulse check/breathing assessment, first response to no pulse no breathing patient, correct depth, rate and position of chest compression and correct chest compression and ventilation ratio $(20-40 \%)$. Due to the inadequate exposure to BLS training, only $14.4 \%$ of the participants were aware of importance of automated external defibrillation in basic life support.

$\begin{array}{lcc}\begin{array}{c}\text { Table 2: Questionnaires to assess knowledge and } \\ \text { awareness. }\end{array} & \begin{array}{c}\text { Number } \\ \text { Questionnaires }\end{array} & \begin{array}{c}\text { Perrect answer) } \\ \text { (Corge }\end{array} \\ \text { Signs of cardiac arrest } & 78 & 34.2 \\ \text { Initial response of cardiac arrest } & 92 & 40.3 \\ \text { Correct vessels for pulse check } & 83 & 36.4 \\ \text { Time for pulse/breathing assessment } & 56 & 24.5 \\ \text { Response to no pulse/breathing } & 75 & 32.8 \\ \text { Depth of chest compression } & 70 & 30.7 \\ \text { Rate of chest compression } & 87 & 38.1 \\ \text { Chest compression position } & 82 & 35.9 \\ \text { Compression ventilation ratio } & 61 & 26.7 \\ \text { Use of AED } & 33 & 14.4\end{array}$

Figure 5 showed the self-grading scoring of basic life support knowledge among the participants. Majority of the participants had below average and poor knowledge regarding BLS skill (46.9\% and $34.2 \%$ respectively)

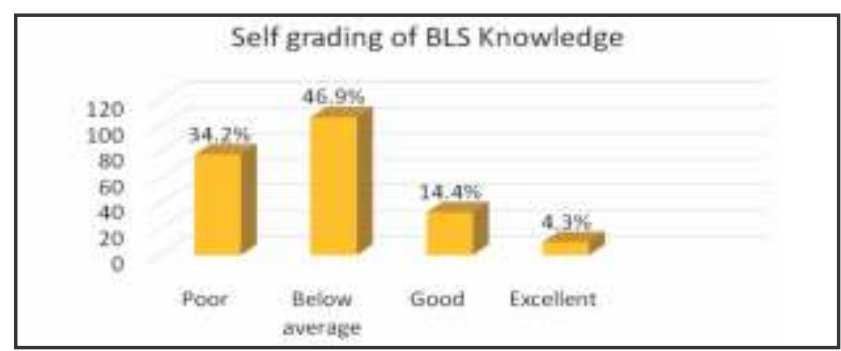

Figure 5: Self- grading of BLS knowledge

On asking about the reason for not having adequate knowledge regarding BLS, majority showed the reason that there was no easy access or non-availability to training facilities in the country $(51.7 \%)$ and also the cost for training was very high (31.5\%) Figure 6.

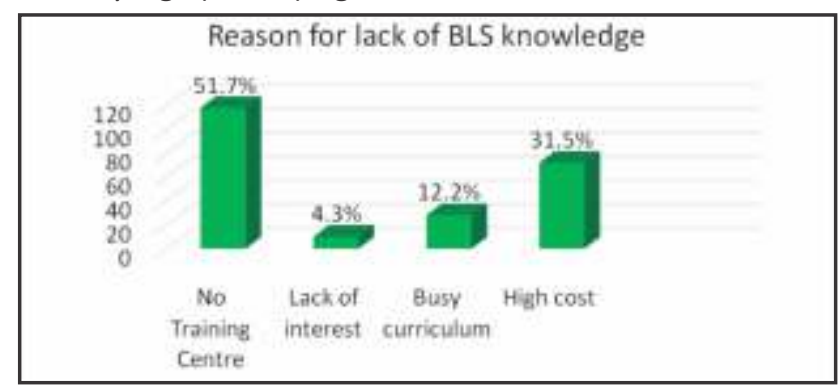

Figure 6: Response for lack of BLS knowledge

\section{DISCUSSION}

A good health professional should be aware and have knowledge of CPR. Basic resuscitation sills are required for all the health care providers as well as the non-medical populations. An effective and timely resuscitation effort can 
significantly improve the outcome of cardiac arrest patient. ${ }^{3}$ This study was conducted on various staffs of Birat medical college to access their awareness.

Majority of the participants in the present study were in the middle age group with the female predominance as the majority of the participants belongs to nursing department Majority have a job experience of one to two years as there is a high tendency to leave the job after one to two years among the nursing staffs due to various personal and institutional work-related issues.

This study projected a fact that only $14 \%$ of the participants had received previous BLS training. This finding could be an alarming data signifying towards lack of awareness and skills for resuscitation. The most disappointing part is those who are working and managing critically ill patients like emergency department, ICU or operation theatres were also devoid of any formal BLS training. This poor result can be best explained by the fact that there are very limited number of training centers in the country and training cost is very high. Also, a low attitude towards the importance of having BLS skills might be one of the major factors for not receiving $B L S$ training. A similar outcome was revealed in a study conducted among medical students by Zaheer $\mathrm{H}$, Haque $Z$ where in Out of 61 students only $9(14.7 \%)$ had taken a BLS (CPR) course while 52 (85.3\%) students had not attended any such course. ${ }^{8}$ Contradictory to our finding, Alotaibi et al had mentioned that $99.1 \%$ of their participants had received previous BLS training. ${ }^{9}$

The study showed majority of the participants had experienced a cardiac arrest situation in patients during their clinical practices in the wards, emergency department, ICU and operation theatre. An interesting finding revealed in the study was despite the fact that only minority had received formal BLS training, the participants who experienced cardiac arrest situation during clinical practices majority of them had started cardiac resuscitation immediately. So, we assumed that even without formal training of BLS, participants were aware of the fact that immediate chest compression could change the outcome of cardiac arrest patient. In a study conducted on 300 Jordanian over 18 years old revealed that the participants who witnessed sudden cardiac arrest comprised 70 (23.3\%) of the total sample. Among those, $42.8 \%$ called the ambulance, $20 \%$ told someone to call for help, $10 \%$ gave chest compression, $10 \%$ gave mouth-tomouth breathing, $8.6 \%$ gave both chest compression and mouth-to-mouth breathing, and $8.6 \%$ just watched and left. ${ }^{10}$ Similarly, Harsha Kumar H. N conducted a study on 377 medical students showed(18.9\%) had undergone prior training in BLS, whereas only $17.7 \%$ had been in a situation which needed BLS/CPR. ${ }^{11}$

The study included 10 questions to assess the awareness and knowledge regarding the BLS skill and practices. Unfortunately, the correct answer of most of the questions were given by less than $50 \%$ of the participants from which it could be predicted that the knowledge and awareness regarding BLS among the various medical staffs of BMCTH was not satisfactory. One possible explanation for not having satisfactory level of knowledge and awareness for BLS was that our study included nursing staffs as major participants and it was obvious that nursing staffs and paramedics were not expected to have adequate skills and knowledge as compared to medical doctors.

Our findings were supported by the similar study done by Zaheer and Carvalho. ${ }^{8,12}$ Both of them demonstrated that the knowledge and awareness of BLS among health care providers in their institute was poor. Similarly, Chandrasekaran $S$ et al found similar unsatisfactory level of knowledge and awareness (majority scored less than $50 \%$ marks) in a study comprising medical, dental and nursing students and faculties in one medical college of Kerala. ${ }^{5}$ Surprisingly, they found that practicing and teaching doctors in this study scored less compared to the nursing teaching faculty. In another study conducted by Srinivas demonstrated the fact that knowledge about the BLS was poor among medical students and was poorer among dental students when study was done among dental, medical, and nursing students. ${ }^{13} \mathrm{~A}$ similar result was projected by a study conducted in Kathmandu Nepal by Roshnana et al where doctors, dentists and paramedics had poor knowledge. ${ }^{14}$

Our study showed that majority of the participants came below average on self-grading of the knowledge and awareness. This fact was truly represented by the fact that majority of the participants were not having adequate knowledge of BLS on assessing with 10 questions. The little over half of them (51.7\%) stated that the reason for lack of knowledge was due to unavailability of training centers which is in fact a major obstacle in teaching BLS skills in Nepal. Another major issue explaining the below average knowledge was that the training cost of BLS was very high in Nepal and the training mannequins were not available easily in most of the teaching institutes. Asmita et al demonstrated the significance of BLS training workshops in improving the knowledge and skills before and after training. They concluded that timely workshop conducted by training centers will improve the knowledge and skill about CPR in BLS significantly. ${ }^{15}$

The study showed that the staffs of BMCTH including medical doctors, nursing staffs did not have adequate knowledge and skill on basic life support. This is a serious issue requiring urgent attention to standardize and improve the BLS skill of these health care professionals.

\section{RECOMMENDATION}

The study elicited some of the major issues for BLS knowledge and skills not having upto the mark. Lack of training centers and high cost were the major ones. The study recommends to develop the training centers at the local level and the cost has to minimize so that it becomes accessible for all the health care personals as well as nonmedical persons. Working on mannequins to practice and perfect their skills is highly recommended for the health care 
providers. Frequent awareness programs should be organized at the general public level with the help of campaigns, media forums and public messages. ${ }^{16}$

\section{CONCLUSION}

This study revealed that the knowledge and awareness of basic life support skills among the various staffs was mostly below average to poor. Significant amount of cost effective BLS trainings must be conducted so as to develop competent staffs by various training centers.

\section{LIMITATION OF THE STUDY}

Study could not include the population from other part of

\section{REFERENCES}

1. Alanazi A, Alsalmeh M, Alsomali O, Almurshdi AM, Alabadi A, AlSulami $M$, et al. Poor basic life support awareness among medical and college of applied medical sciences students necessitates the need for improvement in standards of BLS training and assessment for future health care providers. Middle East J Sci Res. 2014;21:84854DOI:10.5829/idosi.mejsr.2014.21.05.82335

2. Mohaissen MA. Knowledge attitudes towards basic life support among health students at a Saudi women's university. Sultan QaboosUniv Med J. 2017;17:e59-65 DOI: 10.18295/squmj. 2016.17.01.011

3. Sanghavi P, Jena AB, Newhouse JP, Zaslavsky AM. Outcomes after outof-hospital cardiac arrest treated by basic vs advanced life support. JAMA Intern Med. 2015;175(2):196-204. DOI: 10.1001/ jamaintern med.2014.5420.

4. BerdowskiJ,Blom MT, Bardai A, Tan HL, Tijssen JG, Koster RW. Impact of onsite or dispatched automated external defibrillator use on survival after out-of-hospital cardiac arrest. Circulation. 2011;124: 222532PMID:22007075 DOI:10.1161/ CIRCULATIONAHA. 110.015545

5. Chandrasekaran S, Kumar S, Bhat SA, Saravanakumar, Shabbir PM, Chandrasekaran V. Awareness of basic life support among medical, dental, nursing students and doctors.Indian J Anaesth. 2010; 54(2):121-6DOI: 10.4103/0019-5049.63650

6. Ghrayeb FA, Amro NR, Rasheed O, Yagi H, Amro R, Amro B. Knowledge and attitude of basic life support among school teachers in Hebron, Palestine. Int J Res Med Sci. 2017;5:2477-82DOI: http://dx.DOI.org/ 10.18203/2320-6012.jirms20172432

7. Steen PA, Kramer-Johansen J. Improving cardiopulmonary resuscitation quality to ensure survival. CurrOpinCrit Care. 2008; 14:299-304. PMID: 18467890 DOI: 10.1097/ MCC.0b013e3282f827d3

8. Zaheer H, Haque Z. Awareness about BLS (CPR) among medical students: status and requirements.J Pak Med Assoc. 2009 Jan;59(1) :57-9. PMID: 19213385 the country so the result obtained from this study could not be generalized to the other population. The questionnaire used in the study are not validated

\section{ACKNOWLEDGEMENT}

Author would like to thank all the participants in the study for their sincere and active participation

\section{CONFLICT OF INTEREST}

None

\section{FINANCIAL DISCLOSURE}

None
9. Alotaibi O, Alamri F, Almufleh L, Alsougi W. Basic life support: knowledge and attitude among dental students and staff in the college of Dentistry, King Saud University, Saudi J Dent Res 2016 Jan; 7(1):51-56 DOI: 10.4103/IJDS.IJDS_13_17

10. Samiha Jarrah, Mahfuz Judeh, Mohannad Eid AbuRuz.Evaluation of public awareness, knowledge and attitudes towards basic life support: a cross-sectional study. BMC Emergency Medicine 2018; 18:37. DOI.org/10.1186/s12873-018-0190-5

11. Wissenberg $M$, Lippert FK, Folke F, Weeke $P$, Hansen CM, Christensen $\mathrm{EF}$, Jans H, Hansen PA, Lang-Jensen T, Olesen JB, Lindhardsen J, Fosbol EL, Nielsen SL, Gislason GH, Kober L, Torp-Pedersen C: Association of national initiatives to improve cardiac arrest management with rates of bystander intervention and patient survival after out-of-hospital cardiac arrest. JAMA. 2013, 310 (13): 1377-1384. 10.1001/jama.2013. 278483.PMID: 24084923 DOI: 10.1001/jama.2013.278483

12. Carvalho RM, Costa LR, Marcelo VC. Brazilian dental students' perceptions about medical emergencies: A qualitative exploratory study. J Dent Educ 2008;72:1343-9.PMID: 18981213

13. Baduni N, Prakash P, Srivastava D, Sanwal MK, Singh BP. Awareness of basic life support among dental practitioners. Natl J Maxillofac Surg. 2014;5:19-22 DOI: 10.4103/0975-5950.140159

14. Roshana S, Kh B, Rm P, Mw S. Basic life support: Knowledge and attitude of medical/paramedical professionals. World J Emerg Me 2012;3:141-5DOI: 10.5847/wjem.j.1920-8642.2012.02.011.

15. AsmitaChaudhary, Heena Parikh, Viral Dave. CURRENT SCENARIO: KNOWLEDGE OF BASIC LIFE SUPPORT IN MEDICAL COLLEGE.NatI J Med Res. 2011; 1(2): 80-82

16. Zamir Q, Nadeem A, Rizvi AH. Awareness of cardiopulmonary resuscitation in medical-students and doctors in Rawalpindi-Islamabad, Pakistan. J Pak Med Assoc 2012;62:1361-4.PMID: 23866498 